Original Article

\title{
COMPARATIVE STUDY ON THE EFFICACY OF MOMETASONE AND FLUTICASONE NASAL SPRAYS FOR TREATMENT OF ALLERGIC RHINITIS
}

\author{
MAHSHID SADAT MIRMOEZZI ${ }^{1}$, MOHAMMAD SHURIDEH YAZDI², OMID GHOLAMI ${ }^{3 *}$ \\ ${ }^{1}$ Medical Student at the Faculty of Medicine, Sabzevar University of Medical Sciences, Sabzevar, Iran, ${ }^{2}$ Department of Otolaryngology-Head \\ and Neck Surgery, Faculty of Medicine, Sabzevar University of Medical Sciences, Sabzevar, Iran, ${ }^{3}$ Department of Physiology and \\ Pharmacology, Faculty of Medicine, Sabzevar University of Medical Sciences, Sabzevar, Iran \\ Email: omidghphd@gmail.com
}

Received: 31 Oct 2016 Revised and Accepted: 30 Jan 2017

\section{ABSTRACT}

Objective: Allergic rhinitis is the most prevalent of allergic diseases in the world. Nasal corticosteroids are the most applicable drugs for the treatment of allergic rhinitis. In this study, we compared the efficacy of fluticasone propionate (FP) and mometasone furoate (MF) nasal sprays in the treatment of allergic rhinitis based on total nasal symptom score (TNSS) questionnaire.

Methods: For this study, 75 allergic rhinitis patients based on skin prick test and inclusion criteria were randomly assigned to two groups: FP and MF groups. FP group received $200 \mu \mathrm{g}$ dose of FP nasal spray (1 spray/nostril) daily and the MF group received $100 \mathrm{mg}$ dose of MF nasal spray (1 spray/nostril) daily for $8 \mathrm{w}$. The effects of the two agents were compared based on TNSS questionnaire in 0,4 and $8 \mathrm{w}$ after the beginning of the treatment.

Results: Results showed that patients in both groups exhibited significant improvement in their TNSS (P Value $<0.001$ ). A detailed TNSS analysis showed MF to be more effective for relieving all symptoms than FP. The most difference is in decreasing postnasal discharge (PND) symptom. However, the difference for relieving all symptoms is not significant (P value $>0.05$ )

Conclusion: In conclusion, FP and MF are significantly effective in relieving of allergic rhinitis symptoms. Even though, the difference between the two is not significant for $8 \mathrm{w}$ therapy.

Keywords: Fluticasone Propionate, Mometaseone Furoate, Allergic Rhinitis, Total Nasal Symptom Score (TNSS) questionnaire

(C) 2016 The Authors. Published by Innovare Academic Sciences Pvt Ltd. This is an open access article under the CC BY license (http://creativecommons.org/licenses/by/4.0/) DOI: http://dx.doi.org/10.22159/ijpps.2017v9i3.15958

\section{INTRODUCTION}

Allergic rhinitis represents a global health problem that affects 10 to $20 \%$ of the population [1]. Allergic rhinitis is a type I hypersensitivity reaction to exogenous substances like a plant or animal allergens. In this type of reaction, the cutaneous, mucosal-cutaneous or anaphylactic reaction occurs immediately or several minutes after exposure. Diagnostic criteria of allergic rhinitis are recurrent chronic nasal symptoms such as congestion, rhinorrhea (often including postnasal drip), nasal itching, sneezing, and conjunctiva irritation [2]. Allergic rhinitis causes sleep disturbance, impairs psychosocial functioning, and reduces life quality [3].

Allergic rhinitis treatment includes allergen avoidance, pharmacotherapy, and immunotherapy. Intranasal corticosteroids are recommended as first-line therapy for patients with moderate-tosevere Allergic Rhinitis, especially when nasal congestion is a major component of symptoms [4]. To compare the efficacy and safety profile of different available Intranasal corticosteroids for the treatment of Allergic Rhinitis, it is important to understand the difference in chemical structures, their pharmacokinetic and pharmacodynamics properties [4]

Chemical structure of fluticasone and mometasone are displayed in fig. 1. Relative receptor affinity of MF is greater than FP (2244 vs. 1775) [4]. As pharmacokinetic properties, the bioavailability of MF is more than FP ( $46 \%$ vs. $42 \%$ ), and Fraction of unbound intranasal FP in plasma is more than MF (0.1 vs. 0.01) [5]. Based on these pharmacodynamics/pharmacokinetic properties, we respect to have a better clinical outcome for MF than FP.

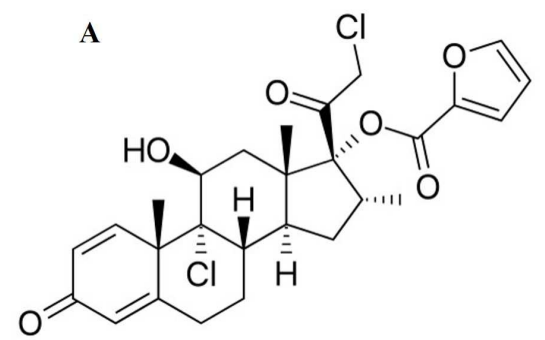

Fig. 1: Structure of mometasone (A) vs. fluticasone (B) [6]
Despite numerous articles about the efficacy of FP and MF nasal spray exist, there is no research about the comparing of the efficacy of these two drugs.
Based on these data, comparing the efficacy of FP and MF on allergic rhinitis symptoms based on TNSS questionnaire is the aim of this manuscript. 


\section{MATERIALS AND METHODS}

\section{Participants}

This study was conducted in the Division of Otolaryngology, Head and Neck Surgery at Vasei Medical University Hospital, Sabzevar, Iran, between August 2015 and March 2016. The study was approved by the vice chancellor for research of Sabzevar University of Medical Sciences and Iranian Registry for Clinical Trials (IRCT2016031419240N2), and written consent was obtained prior to commencement. The study did not receive the MF and FP Corporate Support Grant.

The inclusion criteria were: 1) persistent of Allergic Rhinitis (defined based on clinical examination and verified questionnaire) 2) a positive reaction confirmed by a skin-prick test response. In positive skin-prick test responses, the skin becomes red and swollen with a wheal $>3 \mathrm{~mm}$ in diameter.

The exclusion criteria were: 1 ) infection in the $2 \mathrm{w}$ preceding the initial visit; 2) upper and lower respiratory tract infection within $2 \mathrm{w}$ prior to the study; 3) medication consumption that may affect allergy symptoms (such as oral antihistamines, decongestants, steroids, or leukotriene antagonists) within $2 \mathrm{w}$ prior to the study or during the study period; 4) intranasal corticosteroid use within $2 \mathrm{w}$ prior to the study; and 5) nasal polyp disease.

In total, 75 patients with allergic rhinitis met the inclusion criteria for this study.

\section{Study design}

In the initial screening visit, comprehensive medical and allergy histories were obtained for all participants. Daily-activity diaries were provided to the participants, with instructions to record all symptoms once treatment began. The diaries of patient activity for the preceding $7 \mathrm{~d}$ were also reviewed.

The study design was randomised, prospective, single-blind and controlled. The participants were randomly divided into two groups each participant received a unique code. Of the 75 participants, 6 cases were excluded during the study ( 2 cases from FP group and 4 cases from MF group), 36 cases received FP nasal spray (FP group), and 33 cases received MF nasal spray (MF group). FP group received a $200 \mu \mathrm{g}$ dose of FP nasal spray (1 spray/nostril) daily for $8 \mathrm{w}$, and the remaining participants (MF group) received a $100 \mu \mathrm{g}$ dose of MF nasal spray ( 1 spray/nostril) daily for $8 \mathrm{w}$.

\section{Total nasal symptom score (TNSS)}

Rhinitis symptoms were measured using a 4-point scale. Scores as follows: 0 denoted "none" (no noticeable symptoms); 1 denoted "mild" (symptoms are noticeable but not bothersome); 2 denoted "moderate" (symptoms are noticeable and occasionally bothersome but do not disturb daily activities and sleep); and 3 denoted "severe" (symptoms are generally bothersome and disturb daily activities and sleep). The examiner recorded the patient scores for six nasal symptoms (nasal congestion, rhinorrhea, postnasal drip (PND), nasal itching, smelling disorder and sneezing). Baseline TNSS and each symptom score were calculated as the mean of the scores after 0,4 and $8 \mathrm{w}$ of initiation of treatment [7].

\section{Statistics}

Statistical analysis was performed using IBM SPSS statistics software. All data are expressed as mean \pm standard deviation. An independent sample t-test was used to compare the improvement rates of the mean TNSS for the two groups. A p value $<0.05$ was considered statistically significant. A paired t-test was used to compare the improvement rates of the mean TNSS for each group from $\mathrm{w} 0$ to $\mathrm{w} 4$ and $\mathrm{w} 8$. A $\mathrm{p}$ value $<0.001$ was considered statistically significant.

\section{RESULTS}

A total of 75 patients were enrolled in this study, with 36 patients assigned to an FP group and 33 patients assigned to an MF group. However, 6 patients with incomplete TNSS recordings during the treatment period were subsequently excluded from this study. The mean age of the patients was 21.46 (9.624) years (for FP group) and 20.136 (9.198) years (for MF group). No significant differences were observed between the two groups for baseline demographics or health characteristics (table 1).

Table 1: Demography of characteristics and baseline data of the both fluticasone propionate (FP) and mometasone furoate (MF) groups

\begin{tabular}{lll}
\hline Variables & FP group & MF group \\
\hline Number & 36 & 33 \\
Gender & & $16(48.5 \%)$ \\
Male & $17(47.2 \%)$ & $17(51.5 \%)$ \\
Female & $19(52.8 \%)$ & $20.136(9.198)$ \\
Age $(\mathrm{y})$ & $21.46(9.624)$ & \\
\hline
\end{tabular}

Data are presented as n (\%) or mean (standard deviation)

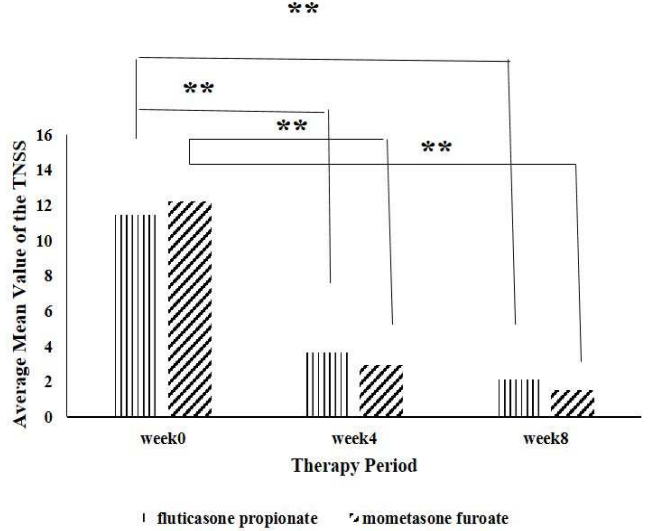

Fig. 2: Mean value of total nasal symptom score (TNSS) in W0, W4 and W8 ( $\left.{ }^{* *} \mathrm{p}<0.001\right)$

For both the FP and MF groups, we analyzed the change in TNSS from baseline (W 0) to Ws 4 and 8 of the treatment. The TNSS was the sum of the six nasal symptom scores. No statistically significant differences were observed between the two groups for baseline (W0) TNSS scores (Baseline TNSS scores for FP group is 11.46 and for MF group is 12.18).

The FP and MF groups experienced improvement in allergic rhinitis nasal symptoms, with symptom improvements of nasal congestion, rhinorrhea, PND, nasal itching, smelling disorder and sneezing achieving statistical significance ( $p$ value $<0.001$ ) from $w 0$ to $w 4$ and from w0 to w8. Improvement in nasal symptoms for MF group was better than FP group, but this difference was not significant ( $p$ value $<0.05$ ) (fig. 2 and table 2).

\section{DISCUSSION}

We found MF sprays to be more effective than FP sprays for relieving nasal symptoms, as evidenced by the differences in TNSS between the two groups. But this difference was not significant ( $p$ value $\leq 0.05$ ). Some studies found that FP and MF are effective and safe in allergic rhinitis [8-17]. Some of their results are consistent with our results, and some of them are not.

Mandl et al. indicated that Mometasone furoate and fluticasone propionate adequately controlled symptoms of perennial rhinitis 
and were well tolerated [8]. Their results are in harmony with our results. In a recent study, Yonezaki et al. found that fluticasone furoate was significantly preferred over mometasone furoate in allergic rhinitis [16]. Their results are not consistent with our results.

In another study, researchers found that following the 4-w therapy, mometasone furoate (MF) nasal spray provided greater improvement compared to fluticasone propionate (FP) nasal spray for symptoms of childhood perennial allergic rhinitis.

Based on their Total Symptom Scores (TSSs) questionnaire, the MF group experienced more effective relief of nasal symptoms, whereas the FP group experienced more effective relief of nonnasal symptoms [2].

Table 2: Changes in total nasal symptom score from baseline ( $\mathrm{W}$ 0) of individual symptoms

\begin{tabular}{|c|c|c|}
\hline & Fluticasone propionate group & Mometasone furoate group \\
\hline \multicolumn{3}{|c|}{ Nasal Symptoms } \\
\hline \multicolumn{3}{|c|}{ Nasal congestion } \\
\hline W0-W4 & $-1.385(0.815)$ & $-1.821(0.548)$ \\
\hline W0-W8 & $-1.821(0.79)$ & $-2.321(0.67)$ \\
\hline W4-W8 & $-0.436(0.502)$ & $-0.5(0.509)$ \\
\hline \multicolumn{3}{|c|}{ Rhinorrhea } \\
\hline W0-W4 & $-1.513(0.854)$ & $-1.679(0.67)$ \\
\hline W0-W8 & $-1.795(0.695)$ & $-1.964(0.508)$ \\
\hline W4-W8 & $-0.282(0.456)$ & $-0.286(0.46)$ \\
\hline \multicolumn{3}{|l|}{ PND } \\
\hline W0-W4 & $-0.897(0.598)$ & $-1.286(0.6)$ \\
\hline W0-W8 & $-1.051(0.605)$ & $-1.357(0.559)$ \\
\hline W4-W8 & $-0.154(0.366)$ & $-0.071(0.262)$ \\
\hline \multicolumn{3}{|c|}{ Nasal itching } \\
\hline W0-W4 & $-1.487(0.823)$ & $-1.714(0.713)$ \\
\hline W0-W8 & $-1.59(0.818)$ & $-1.893(0.786)$ \\
\hline W4-W8 & $-0.103(0.307)$ & $-0.179(0.39)$ \\
\hline \multicolumn{3}{|c|}{ Smelling disorder } \\
\hline W0-W4 & $-1.128(0.656)$ & $-1.357(0.731)$ \\
\hline W0-W8 & $-1.538(0.822)$ & $-1.643(0.911)$ \\
\hline W4-W8 & $-0.41(0.549)$ & $-0.286(0.46)$ \\
\hline \multicolumn{3}{|c|}{ Sneezing } \\
\hline W0-W4 & $-1.41(0.85)$ & $-1.393(0.685)$ \\
\hline W0-W8 & $-1.538(0.822)$ & $-1.464(0.744)$ \\
\hline W4-W8 & $-0.128(0.339)$ & $-0.071(0.262)$ \\
\hline
\end{tabular}

Data are presented as means \pm standard deviation

This study was subject to several limitations. First, recall bias contributed to the inconsistent TNSS results. It is better to employ various examinations, such as nasal peak expiratory flow rate (nPEFR) and the eosinophil percentage in nasal smears, to reduce questionnaire bias. Second, we did not classify the severity of patients' allergic rhinitis in this study; otherwise, the possible response differences to treatment for mild persistent, severeintermittent, or severe persistent types of allergic rhinitis could have been analyzed. At last, we lacked patient data on family member smoking habits and household pets, which are factors that may affect allergic rhinitis symptoms [9].

\section{CONCLUSION}

Our study results show that both intranasal corticosteroid sprays (FP and MF) were effective for managing allergic rhinitis. FP and MF treatment were associated with a significant improvement in mean TNSS (P value<0.001). A further detailed analysis of TNSS indicated that MF was more effective than FP for relieving nasal symptoms (except sneezing, table 2), but this difference was not significant.

In conclusion, the results of our 8-w treatment program showed that FP and MF nasal sprays were effective for improving the symptoms of allergic rhinitis significantly. Although the TNSS for the FP and MF group did not show a significant difference between them.

\section{ACKNOWLEDGMENT}

This study is part of Mahshid Sadat Mirmoezzi M. D. thesis titled: "Comparison of Mometasone Furoate and Fluticasone Propionate Nasal Sprays in the Treatment of Allergic Rhinitis", which has been conducted in the faculty of medicine, Sabzevar University of Medical Sciences.
This Research Project was fully sponsored by Vice Chancellor for Research of Sabzevar University of Medical Sciences with grant number "393010173". The study did not receive the MF and FP Corporate Support Grant.

The funding organization is a public institution and had no role in the design and conduct of the study; collection, management, and analysis of the data; or preparation, review, and approval of the manuscript.

\section{CONFLICTS OF INTERESTS}

We certify that no actual or potential conflict of interest in relation to this article exists.

\section{REFERENCES}

1. Brozek JL, Bousquet J, Baena-Cagnani CE, Bonini S, Canonica GW, Casale TB, et al. Allergic rhinitis and its impact on asthma (ARIA) guidelines: 2010 revision. J Allergy Clin Immunol 2010;126:466-76.

2. Mak KK, Ku MS, Lu KH, Sun HL, Lue KH. Comparison of mometasone furoate monohydrate (Nasonex) and fluticasone propionate (Flixonase) nasal sprays in the treatment of dust mite-sensitive children with perennial allergic rhinitis. Pediatr Neonatol 2013;54:239-45.

3. Craig TJ, Ferguson BJ, Krouse JH. Sleep impairment in allergic rhinitis, rhinosinusitis, and nasal polyposis. Am J Otolaryngol 2008;29:209-17.

4. Giavina-Bianchi P, Agondi R, Stelmach R, Cukier A, Kalil J. Fluticasone furoate nasal spray in the treatment of allergic rhinitis. Ther Clin Risk Manag 2008;4:465-72.

5. Hochhaus G. Pharmacokinetic/pharmacodynamic profile of mometasone furoate nasal spray: potential effects on clinical safety and efficacy. Clin Ther 2008;30:1-13. 
6. Crim C, Pierre LN, Daley-Yates PT. A review of the pharmacology and pharmacokinetics of inhaled fluticasone propionate and mometasone furoate. Clin Ther 2001;23:1339-54.

7. Caliskaner Z, Naiboglu B, Kutlu A, Kartal O, Ozturk S, Onem Y, et al. Risk factors for oral allergy syndrome in patients with seasonal allergic rhinitis. Med Oral Patol Oral Cir Bucal 2011;16:312-6.

8. Mandl M, Nolop K, Lutsky BN. Comparison of once daily mometasone furoate (Nasonex) and fluticasone propionate aqueous nasal sprays for the treatment of perennial rhinitis. The 194-079 study group. Ann Allergy Asthma Immunol 1997;79:237-45.

9. Ratner PH, Meltzer EO, Teper A. Mometasone furoate nasal spray is safe and effective for 1-y treatment of children with perennial allergic rhinitis. Int J Pediatr Otorhinolaryngol 2009;73:651-7.

10. Costa DJ, Amouyal M, Lambert P, Ryan D, Schunemann HJ, Daures JP, et al. How representative are clinical study patients with allergic rhinitis in primary care? J Allergy Clin Immunol 2011;127:920-6.

11. Nathan RA, Berger W, Yang W, Cheema A, Silvey M, Wu W, et al. Effect of once-daily fluticasone furoate nasal spray on nasal symptoms in adults and adolescents with perennial allergic rhinitis. Ann Allergy Asthma Immunol 2008;100:497-505.

12. Fokkens WJ, Jogi R, Reinartz S, Sidorenko I, Sitkauskiene B, van Oene $\mathrm{C}$, et al. Once-daily fluticasone furoate nasal spray is effective in seasonal allergic rhinitis caused by grass pollen. Allergy 2007;62:1078-84.

13. Scadding GK, Lund VJ, Jacques LA, Richards DH. A placebocontrolled study of fluticasone propionate aqueous nasal spray and beclomethasone dipropionate in perennial rhinitis: efficacy in allergic and non-allergic perennial rhinitis. Clin Exp Allergy 1995;25:737-43.

14. Ford LB, Matz J, Hankinson T, Prillaman B, Georges G. A comparison of fluticasone propionate nasal spray and cetirizine in ragweed fall seasonal allergic rhinitis. Allergy Asthma Proc 2015;36:313-9.

15. Okubo K, Okamasa A, Honma G, Komatsubara M. Efficacy and safety of fluticasone furoate nasal spray in Japanese children with perennial allergic rhinitis: a multicentre, randomized, double-blind, placebo-controlled trial. Allergy Asthma Proc 2014;63:543-51.

16. Yonezaki $\mathrm{M}$, Akiyama $\mathrm{K}$, Karaki $\mathrm{M}$, Goto $\mathrm{R}$, Inamoto $\mathrm{R}$, Samukawa Y, et al. Preference evaluation and perceived sensory comparison of fluticasone furoate and mometasone furoate intranasal sprays in allergic rhinitis. Auris Nasus Larynx 2016;43:292-7.

17. Chandra S, Huliraj N, Giriyanna Gowda, Gangaboraiah, Parasuramalu Bg. Randomized, open lable, active-controlled study to assess and compare health-related quality of life with mometasone and formotrol versus fluticasone and formotrol dry powder inhaler in mild to moderate persistent Asthma. Asian J Pharm Clin Res 2015;8:296-8.

\section{How to cite this article}

- $\quad$ Mahshid Sadat Mirmoezzi, Mohammad Shurideh Yazdi, Omid Gholami. Comparative study on the efficacy of mometasone and fluticasone

nasal sprays for treatment of allergic rhinitis. Int J Pharm Pharm Sci 2017;9(3):211-214. 